Gli Elementi d'Euclide e la Critica Antica e Moderna. By Federigo Enriques (col concorso di diversi collaboratori), Libri I-IV. Rome, Alberto Stock, 1925. 323 pp.

The national institute of the history of mathematical and physical sciences has undertaken the preparation of a critical and comprehensive history of a number of the more fundamental branches of the subject. The plan in the present work is to accept the Greek text of Heiberg, and to accompany the new Italian translation with the development of each idea, occasionally referring the reader to more detailed discussions, when the adequate treatment could not be given within the plan of the present book. A list of the more important translations and of commentaries is given, and constant references are made to them. Each definition, axiom, postulate, and theorem is taken up, and its relation to the critical thought of the various ages is given. The text of the translation appears in large type, double leaded lines, and provided with excellent figures. The comments and criticisms are not relegated to foot-notes, but follow immediately that part of the text to which they apply, but printed in different type, and names of authors are displayed. The present volume contains books one to four; each is treated by a different author, but in such a manner that the presentation is homogeneous and unified.

The press work and proof reading have been well done. Apart from a few endings of German adjectives in the foot-notes the only error noticed is the date of the letter from Gauss to Bolyai, p. 50, there given as March 6, 1882 .

The German and English mathematical public are well provided with similar discussions in the works of Simon and of Heath. Three quarters of a century ago Italy had one of the ablest in that of Flauti, but apart from the recent able treatment of Book I by Vacca it is not so well represented by modern treatises. The mathematical literature of Italy and of the world is enriched by this contribution from an entirely competent source.

VIRGIL SNYDER

Traitê du Calcul des Probabilités et de ses Applications. By Émile Borel. Paris, Gauthier-Villars, 1925.

Fascicule I, tome I. Principes et Formules Classiques du Calcul des Probabilités. Leçons professées par É. Borel, redigées par René Lagrange. $160 \mathrm{pp}$.

Fascicule III, tome II. Mécanique Statistique Classique. Leçons professées par E. Borel, redigées par Francis Perrin. 148 pp.

These two works are parts of a proposed treatise on the theory of probability that evidently aims to be the most complete work of its kind. The first was written by René Lagrange from lectures by Professor Borel. It covers that part of the theory of probability which has come to be considered as classical. It is divided into two fairly distinct parts. In the first part, starting in the usual way with definitions, the author takes up the topics of discontinuous, continuous, and denumerable probabilities. The inclusion of this last topic is one of the characteristics of this work 
which distinguish it not only from works on probability by other authors but from Borel's earlier works on probability. Another characteristic is the introduction of the terms "problems of the first order," "problems of the second order." Problems of the first order are those concerned with the finding of a single probability, while those of the second order deal with the distribution of probabilities. The six classes of problems arising out of these two types of problems in each of the three kinds of probability form the basis of the arrangement of the subject matter. The second part of this work is devoted to a general discussion of the functions that arise in statistics with special emphasis on the theory of moments.

The second work was written by Francis Perrin from lectures by Borel. It is devoted to classical statistical mechanics and the kinetic theory of gases presented in much the usual arrangement. Borel takes considerable pains to show that the idea of probability can be introduced naturally into mechanics without making unreasonable hypotheses, and he spends considerable time on the bonds which unite the fundamental laws of kinetic theory with the principles of mechanics.

These two fasciculi are but a small part of what promises to be a great treatise on the theory of probabilities and its applications. While they intentionally stick to the older and more established topics they are written with a clarity and an elegance of detail and arrangement that prophesies much for the complete work. When finished there should be another great French work on probabilities to be placed besides the works of Laplace, Poisson, Bertrand, Poincaré, and the earlier work of Borel.

\section{A. R. CRathorne}

Wie man einstens rechnete. By E. Fettweis. Mathematisch-Physikalische Bibliothek, Band 49. Berlin, Teubner, 1923. $56 \mathrm{pp}$.

This small volume, issued for a quarter (one gold-mark) represents a fine type of popular scientific work common in Germany and Italy. There are chapters on the primitive origins of counting and reckoning, on Egyptian, Babylonian, Mayan and Chinese arithmetic, on computation among Greeks and Romans, on the abacists of the middle ages, on the arithmetic of the Hindus and of the Arabs, on the development of the Hindu-Arabic methods in the West, and on reckoning with counters.

The author is well acquainted with the modern literature of his subject. In the section on the Greek abacus, however, the author permits himself to enlarge upon what is actually known concerning the methods of computation with that instrument in ancient Greece. The methods of division and the like described by the author are found only in late times, about 1000 A.D. and thereafter, not in ancient times as stated here. In the treatment of Hindu mathematics, the methods of the early European works are included by Fettweis; we do not certainly know them to have been employed by the Hindus, although there is evidence showing that probability.

Any one interested in the history of arithmetic will find in this little volume a stimulating and entertaining account of the development of the subject.

L. C. KARPINSKI 